\title{
Studies on experimental retinitis
}

\section{Light and electron microscopy}

\author{
A. N. BARBER*, G. CATSUlis*, and R. J. CANGElOSI** \\ From the Departments of Pathology* and Ophthalmology**, Louisiana State University Medical \\ Center, New Orleans, Louisiana
}

Machemer (1968) and Kroll and Machemer ( $1969 a, b)$ studied the ultrastructure of mechanically detached retinae in owl and rhesus monkeys. They found that in detached retinae the outer segments of the rods and cones became disorganized; when the retinae were reattached, however, the saccules of the outer segments were regenerated by the inner segments and the retinae resumed their normal architecture.

Our interest has been in the pathology of retinitis and the ensuing irreversible changes in the detached retina. Ocular siderosis creates intraocular inflammation which primarily affects the retina (Cibis and Yamashita, I959; Hogan and Zimmerman, 1962). By injecting soluble iron into the vitreous of rabbits we produced a severe retinitis which was studied by light and electron microscopy. The purpose of this paper is to report the ultrastructural changes that occurred in the retina during and after experimental inflammation.

\section{Material and methods}

Saccharated iron oxide* or iron-dextran complex** was injected directly into the vitreous of albino or pigmented rabbits. Various doses were used: $0.5,1,1 \cdot 5$, and 3 minims. A half-inch 27 gauge hypodermic needle was inserted into the vitreous through the sclera and pars plana about $5 \mathrm{~mm}$. behind the temporal limbus, slanting the needle slightly posteriorly in order to avoid the lens. Only one injection was given, always into the right eye; the left eye remained untreated as a control. Other control eyes were taken from animals that had received no treatment of any kind. The animals were killed at intervals of $1,6,12,18$, and 24 hours; at 1, 2, and 6 weeks; and at 4 and 6 months.

For light microscopy, the eyes were fixed in neutral formalin, embedded in paraffin, and sections stained with haematoxylin and eosin, Prussian blue, and the Quinche method for demonstrating iron (Lillie, 1965).

For electron microscopy, retinal samples were taken from calottes, fixed in buffered I per cent. osmium tetroxide for $\mathrm{I} \frac{1}{2}$ hours, dehydrated in graded alcohols, and embedded in Maraglas. Sections were cut on a Porter-Blum microtome, stained with lead citrate, and examined and photographed in a RCA EMU ${ }_{3} \mathrm{~F}$ microscope.

This research was supported by Grant No. NB-07398 of the Neurological Diseases and Blindness Division of the Nationa IInstitute of Neurological Diseases and Blindness of the Department of Health, Education and Welfare, Public Health Service, U.S.A.

* Proferrin-Merck and Company, West Point, Pennsylvania, U.S.A.

** Imferon-Lakeside Laboratories, Inc., Milwaukee, Wisconsin, U.S.A. 


\section{Results}

\section{LIGHT MICROSCOPY}

Intraocular injections of the iron-polysaccharide complex caused the following temporal sequence of changes in the retina. The earliest change noted by light microscopy was iron staining of the inner limiting membrane. Then came diffuse iron-positive staining suggesting diffusion of iron into the retina. Localization of iron-positive particles was next observed in the photoreceptor cells, and then the Müller fibres became swollen and later hyalinized and fragmented (Fig. I). An acute inflammation followed with masses of leucocytes and monocytes in the vitreous. An inflammatory infiltrate also appeared in the choroid, and, when Bruch's membrane fragmented, the cells passed into the retina.

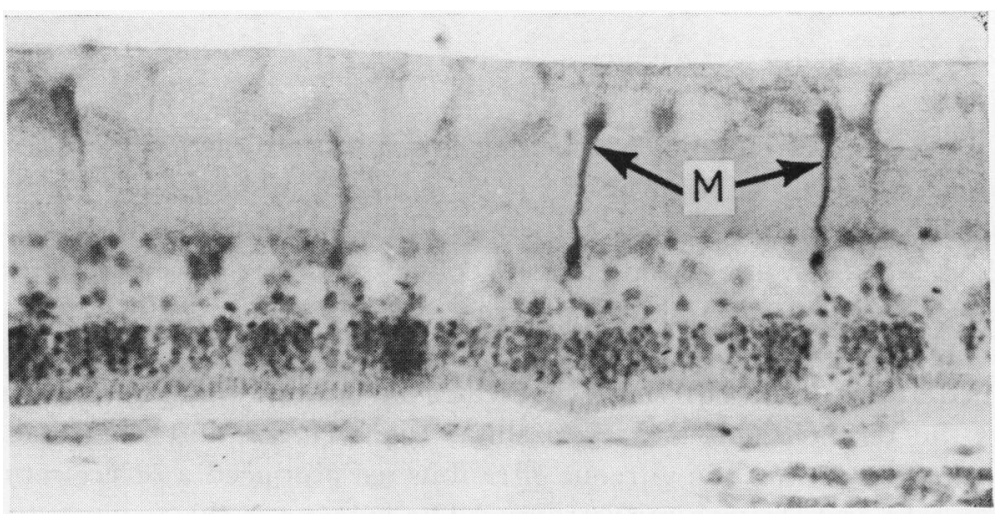

FIG. I Rabbit retina ơ 48 hrs after 0.5 minim iv intraocular injection of $\mathfrak{6}$ saccharated iron oxide. $\overrightarrow{0}$ Hyalinized Müller fibres are beginning to fragment $\vec{T}$ $(M)$. Haematoxylin and $\mathbb{D}$ eosin. $\times 200$

A 3-minim intraocular injection caused a more intense inflammatory reaction. Nunf erous eosinophils and monocytes were present in the vitreous, uvea, and retina by $\overrightarrow{1} \overrightarrow{8}$ hours. The inner and outer limiting membranes fragmented by 24 hours and inflammatory cells passed freely to the retina from both the vitreous and choroid.

Degeneration of the photoreceptor cell nuclei and the rod segments followed and the $\overrightarrow{\overrightarrow{0}}$ debris was phagocytized by macrophages. At 3 to 6 months after injection the retina was an atrophic membrane with areas of gliosis and detachment (Figs 2 and 3 ).

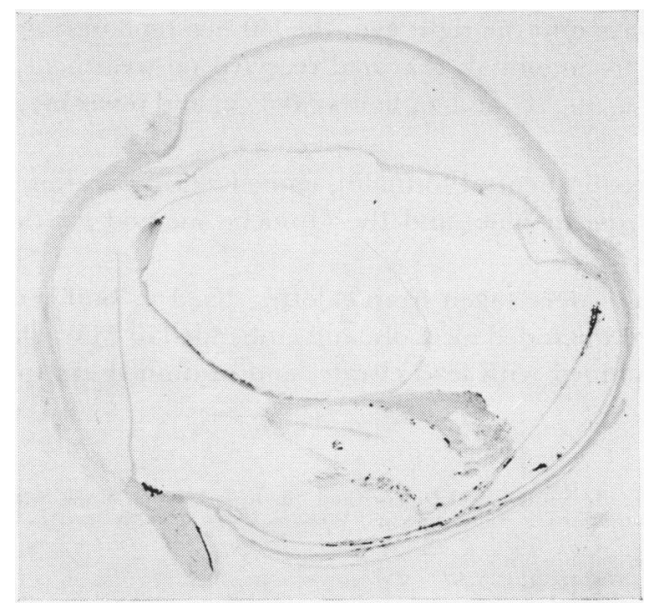

FIG. 2 Albino rabbit eye 6 months after I-minim 을 intraocular injection of iron-dextran complex. The $D$ vitreous in the lower half of the eye still contains clumps of degenerating macrophages filled with iron. The retina consists of atrophic strands and iron is 0 present on the optic disc and in the sheaths of the $N$ nerve. Prussian blue. $\times 7$ 


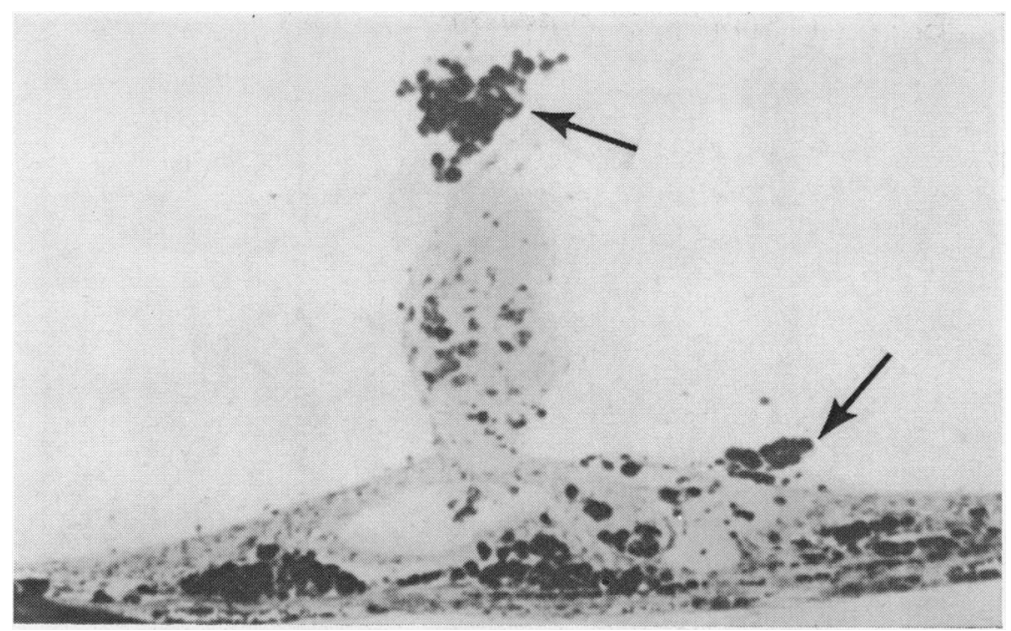

FIG. 3 High-power view of the retina in the eye shown in Fig. 2. Dense fibres and a few glial cells remain. Prussian blue. $\times 200$

\section{ELEGTRON MIGROSGOPY}

Details of the electron microscopic examination, with controls shown in Figs 4, 5, 6, and 7 for comparison, are described more fully in the legends accompanying the illustrations. However, in general they confirm and elucidate the results seen by light microscopy.

Fig. 8 shows retinal detachment during the early stages of chorioretinal inflammation. (Compare with control shown in Fig. 4.) Many of the rod segments are fragmented and cellular debris has been scavenged by macrophages which have invaded the subretinal space. A portion of a rod outer segment can be seen in the sytoplasm of a macrophage (arrow). Fig. 9 shows a comparable stage in an albino rabbit. In this instance many fragments of rod outer segments are present in vacuoles deep in the cytoplasm of the pigment epithelial cells (arrows), and there is a relative increase in the number of mitochondria.

Marked degeneration of the nuclear layers followed. In Fig. Io the nuclei of the rods are irregular in shape and vacuolated, and concretions of nuclear material are scattered throughout the cytoplasm. Numerous breaks are present in the outer limiting membrane (arrows). (Compare with control shown in Fig. 5.)

Fig. I I shows a slightly later stage. The rod nuclei and inner and outer segments have disappeared, leaving the brush borders of the Müller fibres facing the subretinal space. An interesting feature at this stage is the presence of dilated cisternae in the granular endoplasmic reticulum. Macrophages, swollen with particulate matter, are also a prominent feature.

Large areas of retinoschisis developed by the $5^{\text {th }}$ day. Cystoid spaces appeared in either the inner or outer plexiform layer, coalesced, and formed long splits in the retina. Three cystoid spaces are seen in the electron micrograph shown in Fig. 12. They involve mainly Müller fibres and are separated by nerve fibres in the inner plexiform layer. This illustration should be compared with controls shown in Figs 6 and 7. Comparison with the photomicrograph shown in Fig. I suggests that fragmentation of Müller fibres seen by light microscopy may explain the appearance of the cystoid -spaces. The inner ends of the Müller fibres are also swollen and show an increase in the amount of agranular endoplasmic reticulum which corresponds to the swollen appearance of the fibres in Fig. I.

Electron microscopy was particularly revealing in thestudy of the healing processin experimental retinitis. After degeneration and removal of the cellular elements of the retina and 


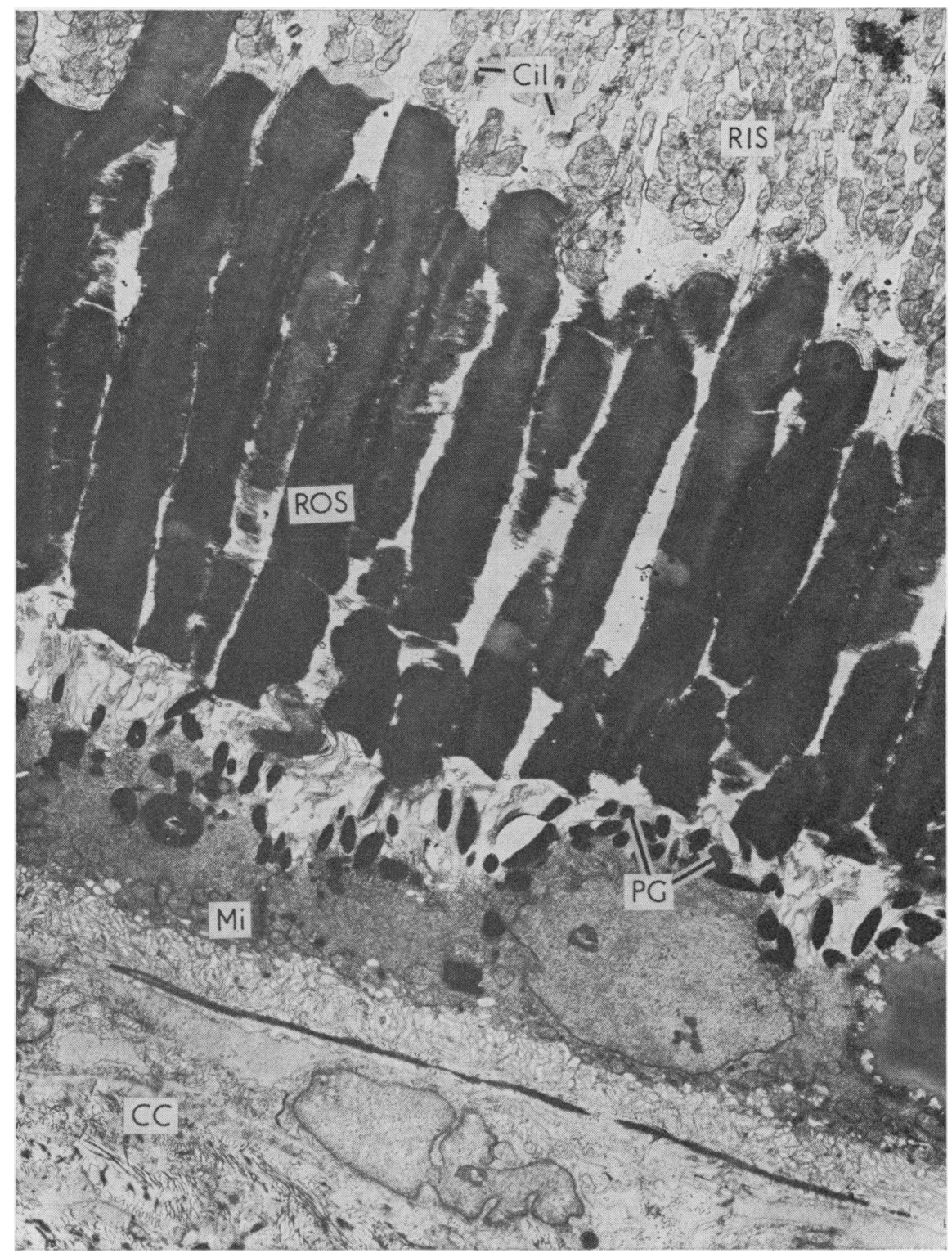

FIG. 4 Ciontrol eye. Low-power electron micrograph of rabbit pigment epithelium. The external third of the epithelial cells is composed of a deep complex of basal infoldings of the cell membrane which lies adjacent to an inner layer of mitochondria $(\mathrm{Mi})$. The inner third of the cells contains large disc or irregularly-shaped pigment granules $(P G)$. Many of the granules occupy the ends of microvilli which cover the inner surface of the cells and penetrate between the rod outer segments. Several connecting cilia can be seen between the inner and outer segments. $\times 5,000$ RIS, rod inner segment; ROS, rod outer segment; Gil, connecting cilium; CC, choriocapillaris. $\times 5,000$

the inner and outer segments of the rods, the remaining Müller fibres were united to each other by the formation of desmosomes. Attachment zones were also formed between outer ends of the Müller fibres and the pigment epithelium (Figs 1 3, I4, and I5). (Compare with controls shown in Figs 4 and 5.) In Figs I 3 and I 4 a the brush borders are still present on the ends of a few Müller fibres, but have disappeared in the region of reattach- 


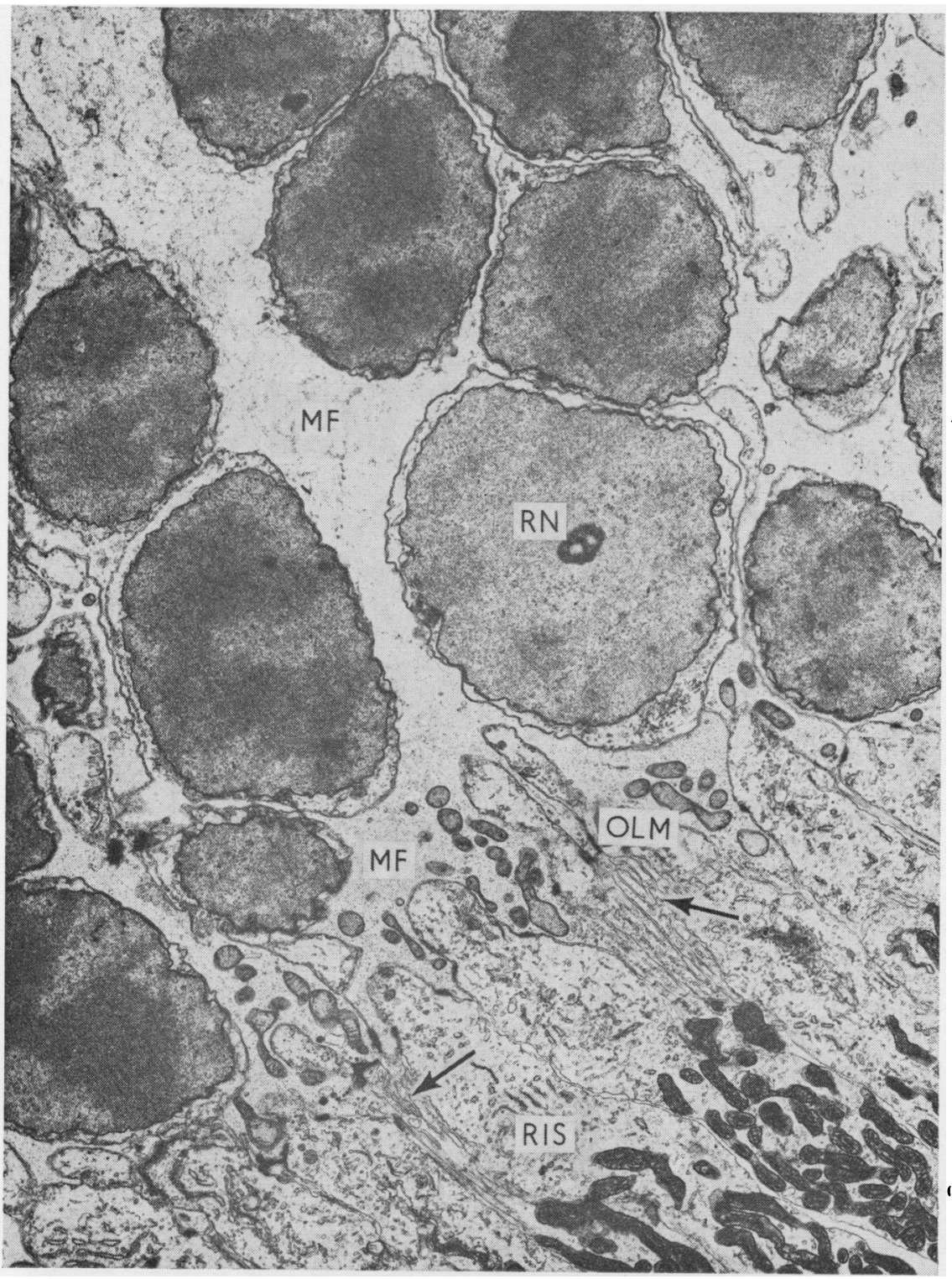

FIG. 5 Control eye. Low-power electron micrograph which shows outer nucleus layer, and external limiting membrane (OLM) composed of desmosomes (zonular adherens) which attach the Müller fibres $(M F)$ to the rod inner segments (RIS). The brush borders of the Müller cells are indicated by arrows.

$\mathrm{RN}$, rod nuclei. $\times 5,000$

ment (arrows). During the healing process the epithelial cells were very active, proliferated, and formed mounds several cells deep; some became distended by large vacuoles as seen in Fig. $14 \mathrm{~b}$.

The desmosomes which united the Müller fibres with the epithelial cells were very strong. Fig. I 5 shows an area where the epithelium was accidently torn from Bruch's membrane, yet it remained with the Müller cells even though the attachment zones were of recent formation. 


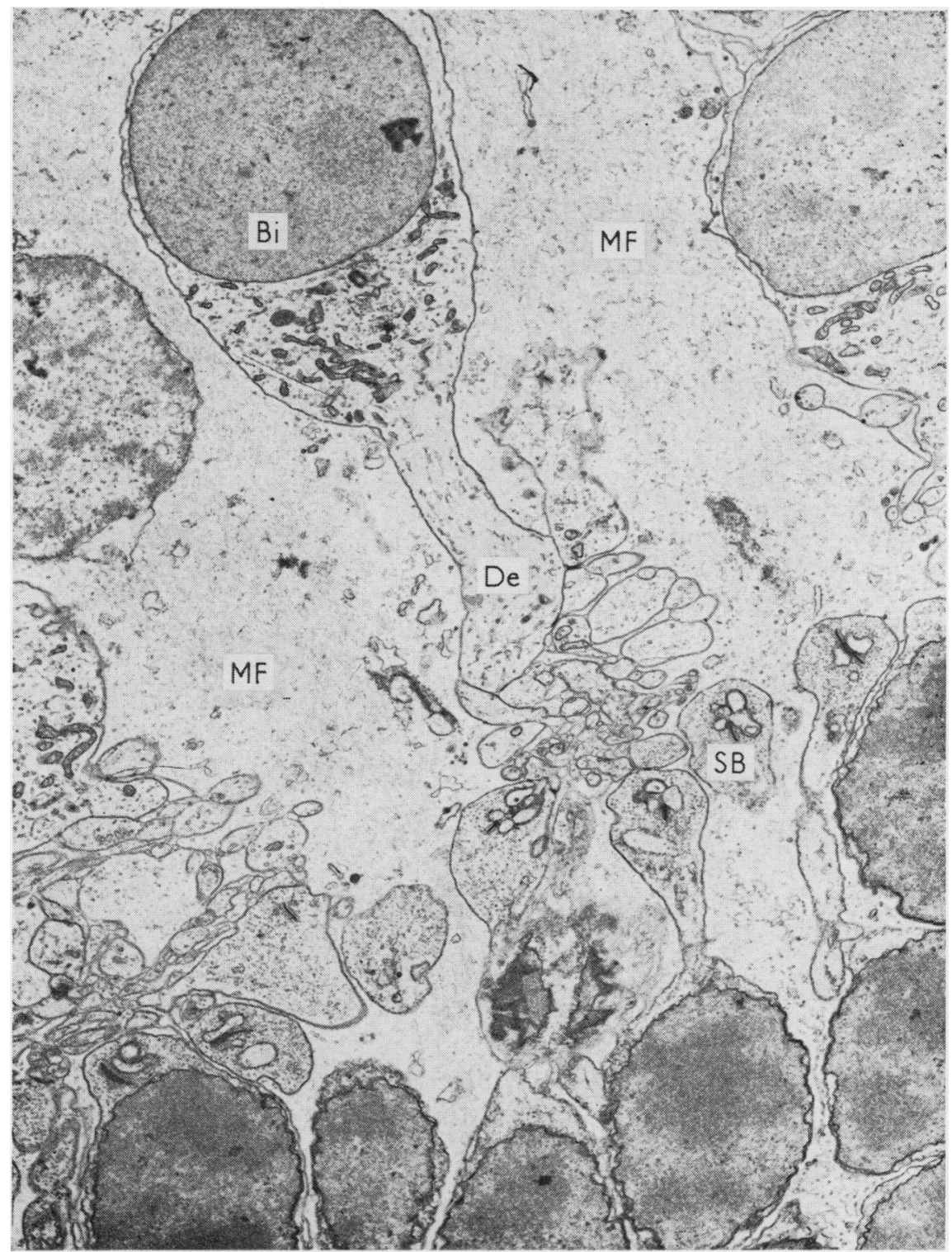

FIG. 6 Control eye. Low-power view of inner and outer nuclear layers and outer plexiform layer of rabbit retina. Several bipolar cells $(B i)$ are present in the inner nuclear layer and their dendrites $(D e)$ extend into the outer plexiform layer. Numerous synaptic bodies $(S B)$ with synaptic vesicles are present in the rod axones. Müller fibres $(M F)$ fill the extracellular spaces between the outer cellular elements. $\quad \times 7,000$

\section{Comment}

The main contribution of this study is the demonstration of the ultrastructure of degenerative changes during inflammation of the retina and the resolution of these changes. In contrast to reattachment of the retina after mechanical detachment studied by Kroll and Machemer ( $1969 \mathrm{a}, \mathrm{b}$ ), the reattachment after retinal inflammation occurs as a result of the formation of new connections (desmosomes) between cells that were not originally attached; that is, the Müller fibres and the pigment epithelial cells. 


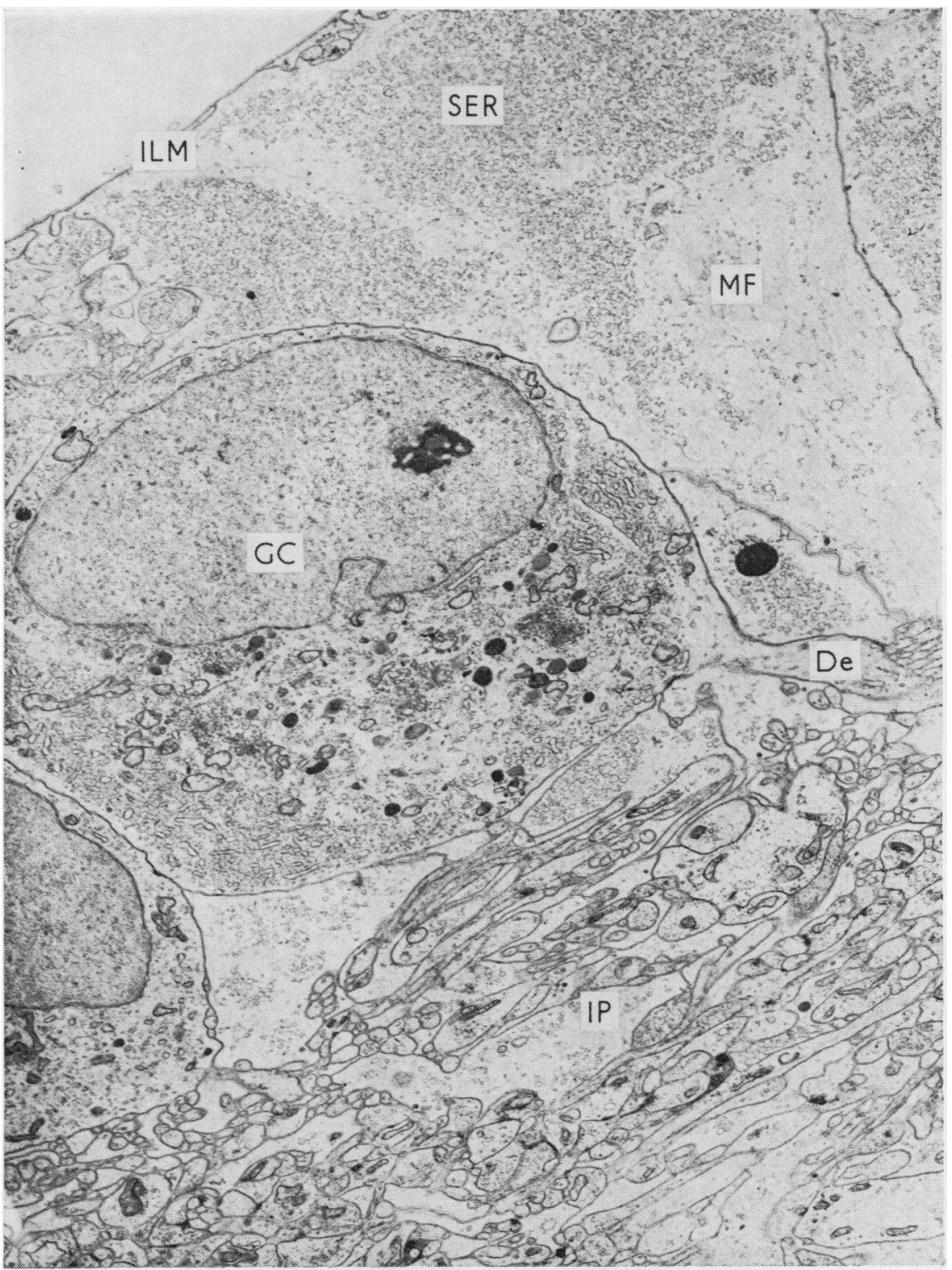

FIG. 7 Control eye. Electron micrograph of the inner portion of rabbit retina. A ganglion cell $(G C)$ with dendrite $(D e)$ entering the inner plexiform layer $(I P)$ is seen in the centre. Müller fibres $(M F)$ fill the extracellular space and their expanded ends form the internal limiting membrane $(I L M)$. Agranular endoplasmic reticulum (SER) is a prominent feature of the inner ends of the Müller fibres. $\quad \times 7,000$

The reorganization of a new outer limiting membrane by formation of desmosomes between the viable Müller fibres that remain in the atrophic retina is also an interesting feature of the healing process. These attachment zones reunite the elements of the retina into an atrophic, but intact membrane.

Many of the degenerative changes seen in our material were described by Shakib and Ashton (1966) in their comprehensive study of the ultrastructural changes in the retina following ischaemia. The swelling of the nuclei and their final rupture, concretions of 


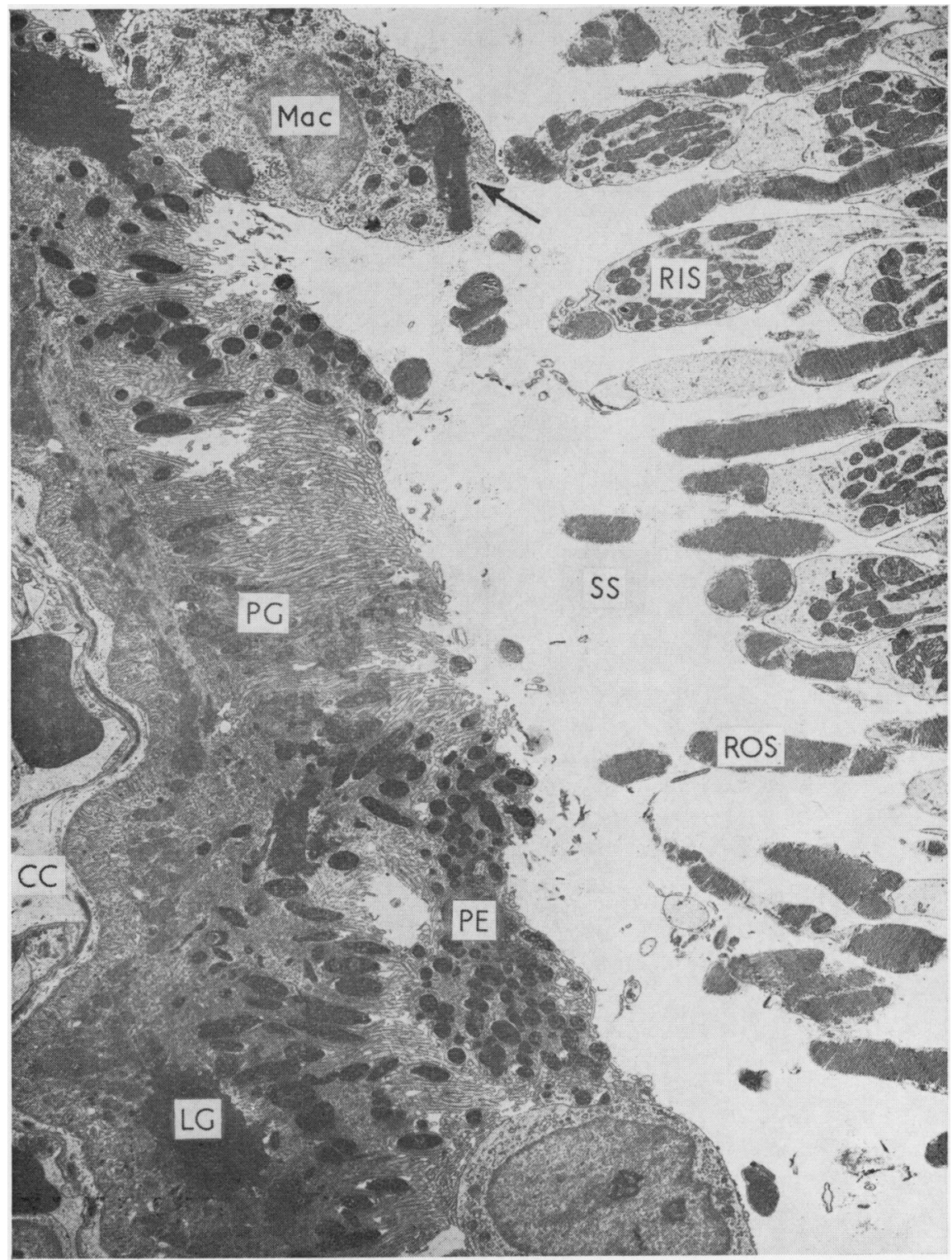

FIG. 8 3-minim intraocular injection of iron-dextran complex after I4 days. This low-power electron micrograph shows a lesion where the retina is detached. Many rod outer segments have been destroyed. Macrophages (Mac) have entered the subretinal space and ingested cellular debris. A fragment of a rod outer segment (ROS) is present in the cytoplasm of a macrophage (arrow). Some of the pigment granules (PG) have withdrawn to the interior of the epithelial cells but many remain at the tips of the macrovilli. In the centre a pigment epithelial cell $(P E)$ is detached from the epithelium.

LG, lipid globule; CG, choriocapillaris; SS, subretinal space. $\quad \times 4,000$

nuclear material in the cytoplasm, and dilatation of the cisternae of the granular endoplasmic reticulum found in our material agree with their observations.

We would not confirm their observations on the origin and fate of the phagocytic cells in the pig, since the rabbit retina is free of blood vessels except on the inner surface near 


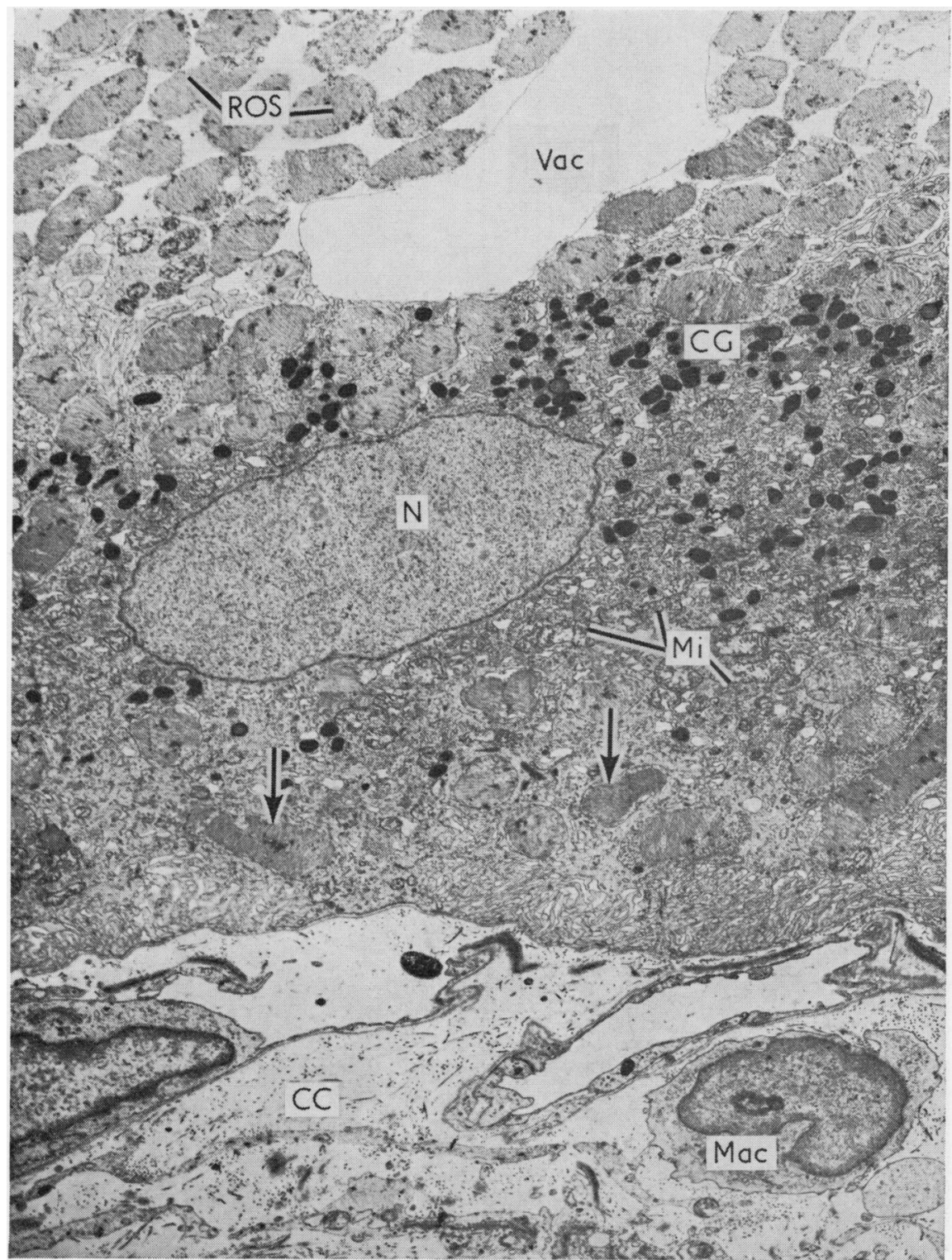

FIG. 9 I-minim intraocular injection of iron-dextran complex after 5 days. Electron micrograph of retinal epithelium of an albino rabbit. Microvilli on the apical surface of epithelial cells surround fragments of rod outer segments (ROS). Many of the fragments are within vacuoles deep in the cytoplasm (arrows), and there is a relative increase in mitochondria. Numerous cytoplasmic globules $(C G)$ are also scattered throughout the cytoplasm.

$\mathrm{N}$, nucleus; Mi, mitochondria; Vac, vacuole; CC, choriocapillaris; Mac, macrophage. $\times 5,400$

the optic disc. Most of the macrophages seen by us arrived from outside the retina at least during the early stages of inflammation. They appeared first in the vitreous and were mainly eosinophils with a few monocytes. Almost immediately afterwards they were found in the stroma and blood vessels of the choroid. As soon as breaks developed in the inner limiting membrane, the macrophages entered the retina. A larger 


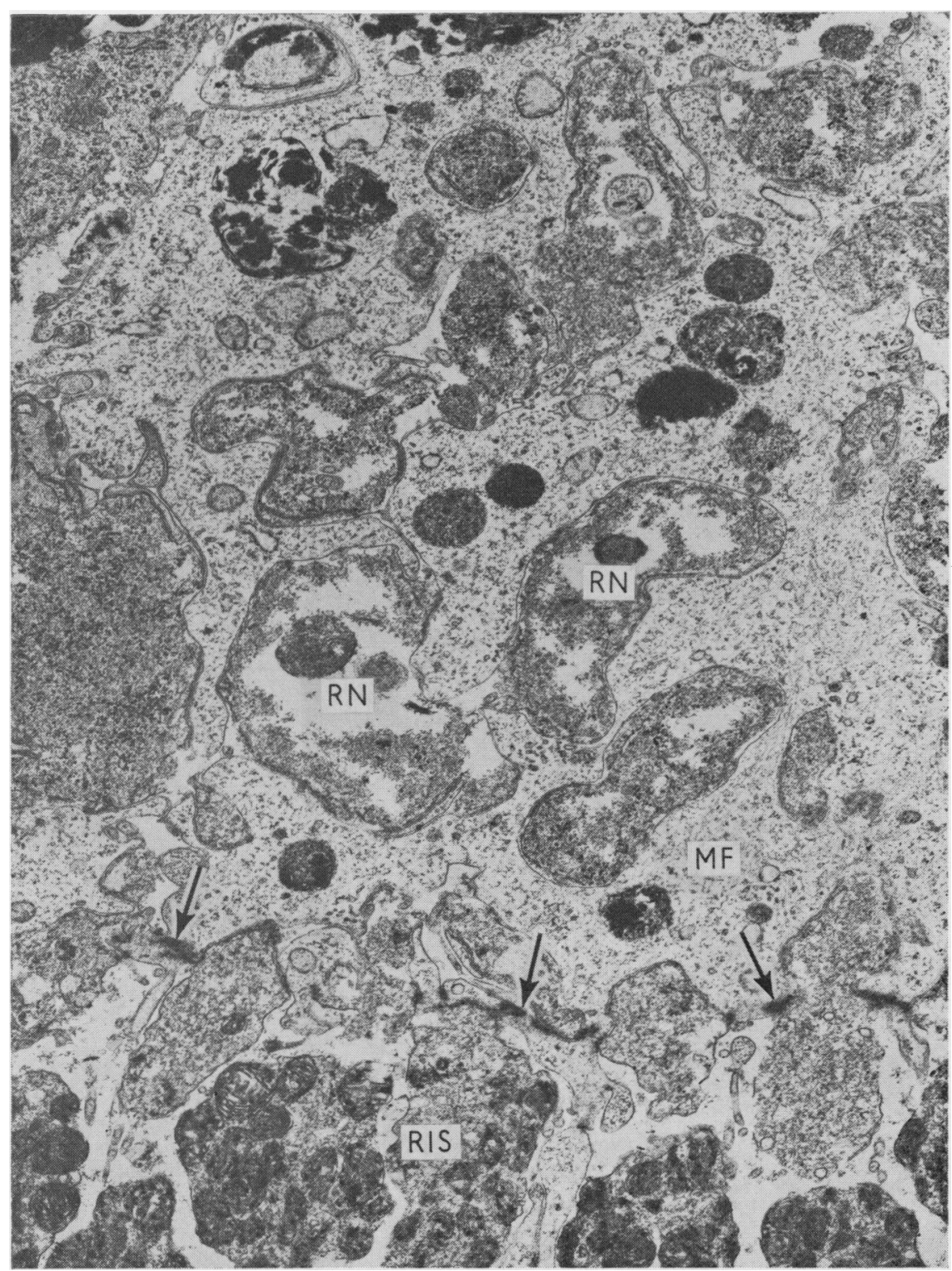

FIG. IO I-minim intraocular injection of iron-dextran complex after 3 days. Electron micrograph, showing rabbit retina. Marked degeneration of the rod nuclei $(R \mathcal{N})$ has occurred and the external limiting membrane (arrows) is disorganized.

MF, Müller fibres; RIS, rod inner segment. (Compare with Fig. 6) $\times$ I I ,250

number, however, entered the subretinal spaces through breaks in Bruch's membrane, and migrated thence to the retina. By the time the macrophages could be identified in the retina, their origin could not be differentiated as was possible in the work of Shakib and Ashton (1966).

It is interesting to speculate about the healing process in experimentally-produced retinitis and the condition known as "healed chorioretinitis" in humans. Electron microscopic studies on primates are in progress in this laboratory to determine whether 


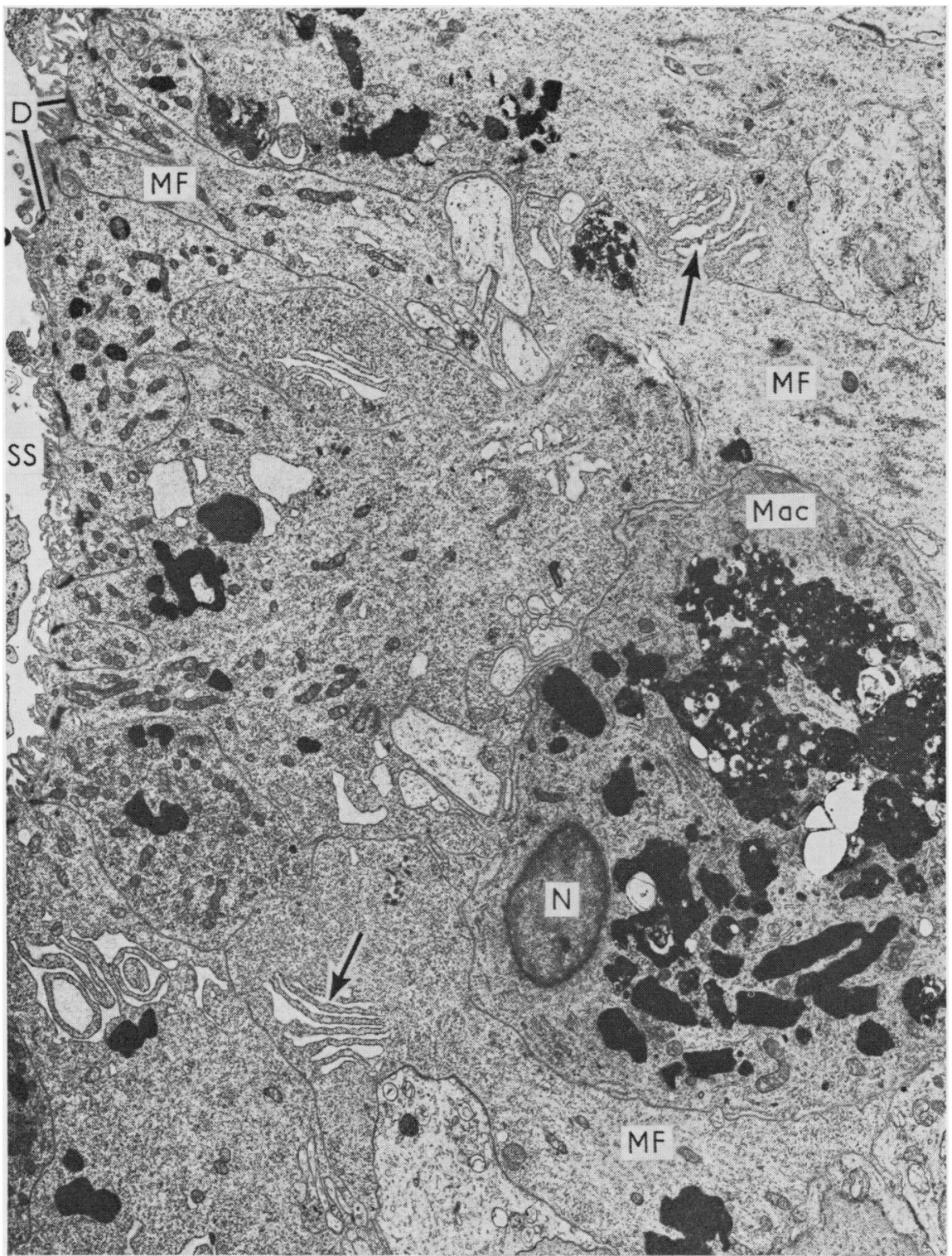

FIG. I I I-minim intraocular injection of iron-dextran complex after 14 days. Electron micrograph of outer portion of rabbit retina shows absence of rods and their nuclei. $A$ macrophage can be seen on the right. Dilated cisternae of the granular reticulum are indicated by arrows. Desmosomes $(D)$ unite the Müller fibres $(M F)$ and the brush borders of these fibres are short and reduced in number.

Mac, macrophage; N, nucleus; SS, subretinal space. (Compare with Figs 2 and 3 ) $\times 5,250$

or not the adhesions formed between the retina and choroid after chorioretinal inflammation are desmosomes.

\section{Summary}

Experimental retinitis, created by intraocular injections of an iron-polysaccharide complex, has been studied by means of light and electron microscopy. The electron microscopy 


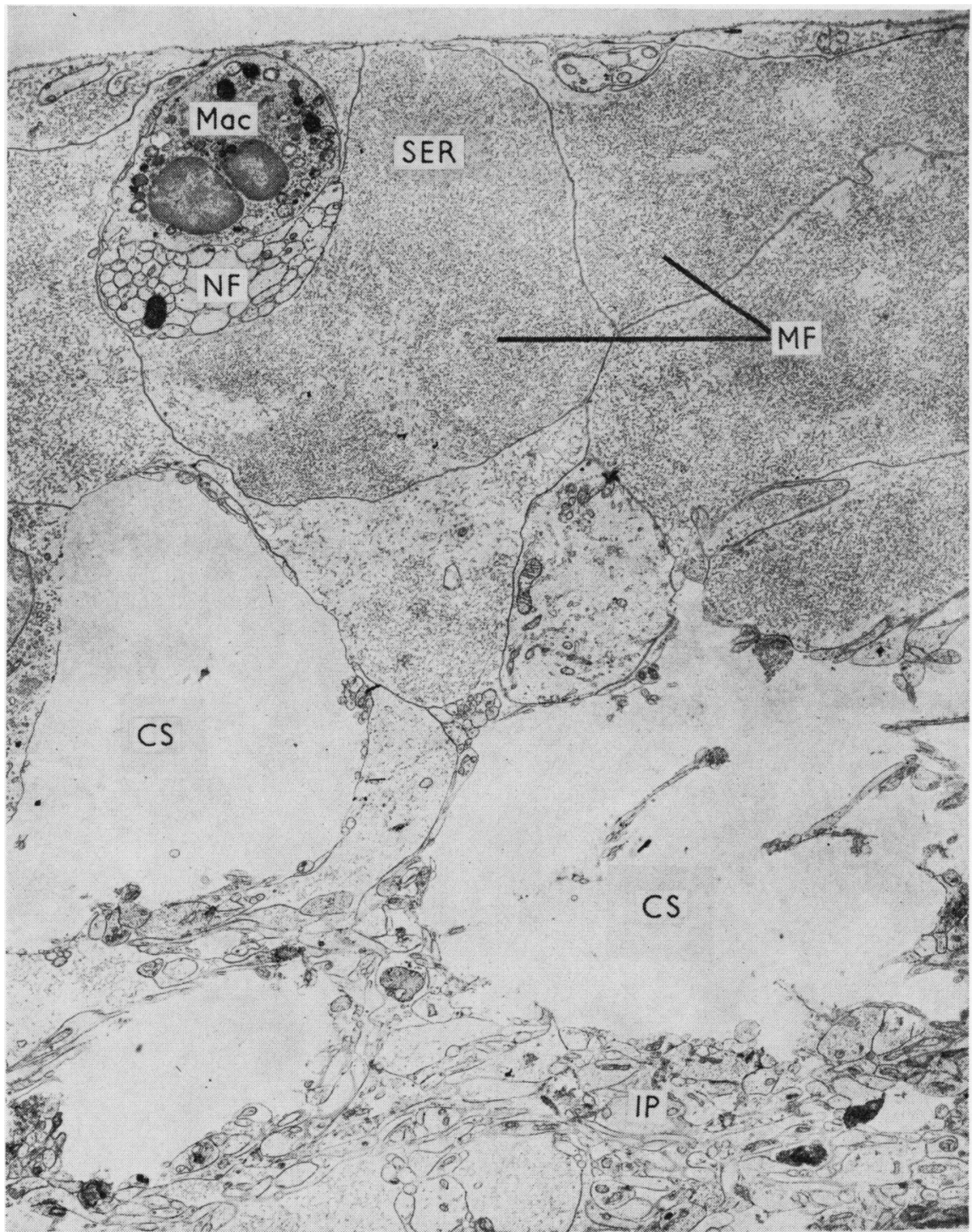

FIG. I2 3-minim intraocular injection of iron-dextran complex after 24 hours. Low-power electron micrograph shows an increase in the amount of granular reticulum $(S E R)$ in the vitreal ends of the Müller fibres $(M F)$ and cystoid spaces $(C S)$ in the inner plexiform layer $(I P)$. The cystoid spaces are in areas where the Miller fibres are missing. A macrophage (Mac) is seen at the left.

NF, nerve fibres. (Compare with Fig. 7) $\times 4,200$

confirmed the light microscopy and added new information, especially about the healing process.

The salient facts are:

(r) Early destruction of the photoreceptor cell nuclei and their segments;

(2) Retinoschisis or splitting of the inner or outer plexiform layers by fragmentation of Müller fibres; 


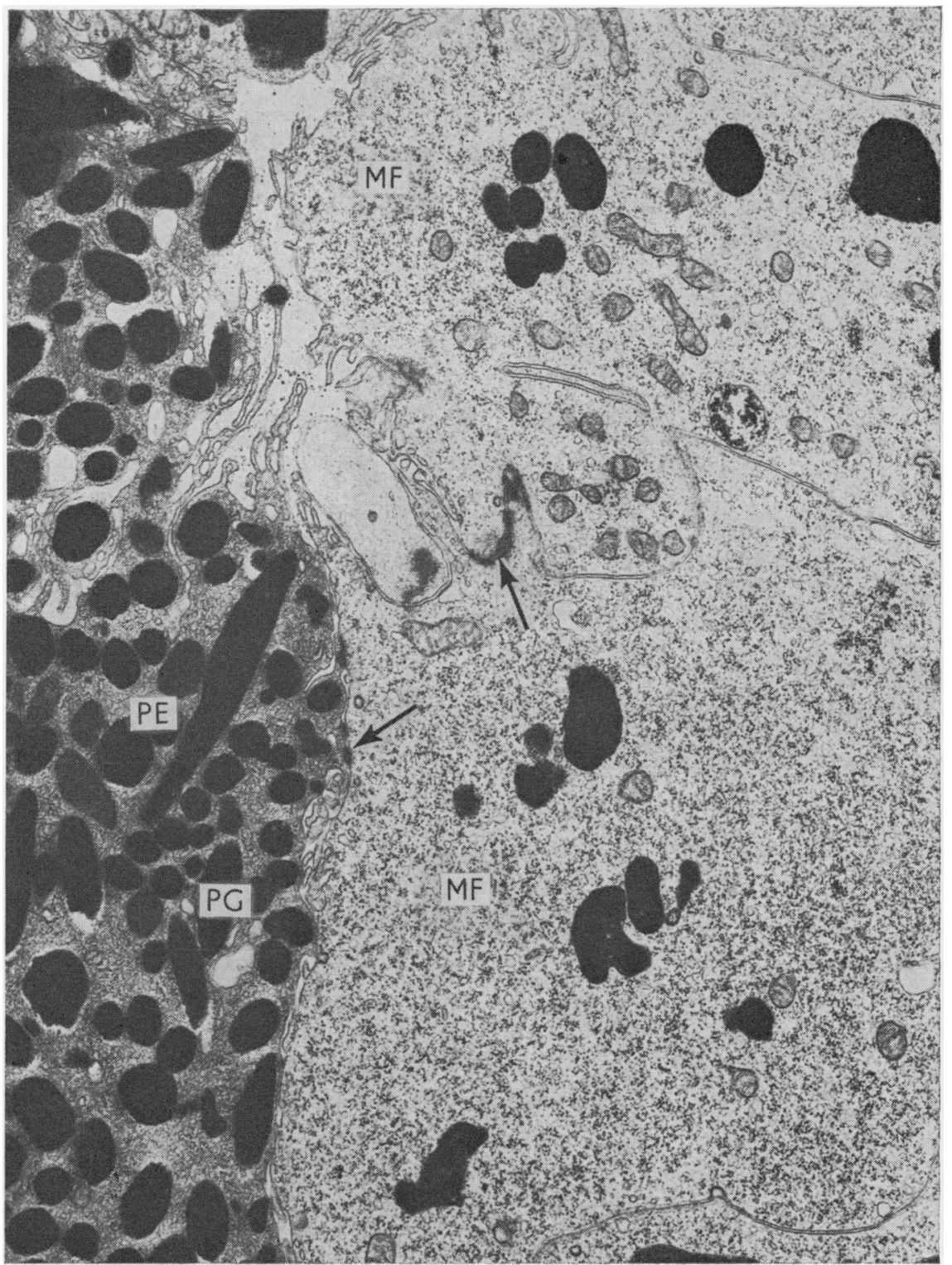

FIG. I3 I-minim intraocular injection of iron-dextran complex after I 4 days. High-power electron micrograph of retinal reattachment. The rod nuclei and segments have disappeared. Desmosomes (arrows) form an attachment zone uniting the outer ends of Müller fibres to each other, forming a new outer limiting membrane, and other desmosomes attach the fibres to the pigment epithelium, thus reattaching the atrophic retina to the epithelium. Notice the loss of the brush borders of the Müller fibres and retraction of the microvilli of the pigment epithelial cells.

MF, Müller fibre; PE, pigment epithelium; PG, pigment granule. (Compare with Fig. 4) $\times$ I $5,75^{\circ}$

(3) Formation of a new outer limiting membrane by desmosomes which unite the Müller fibres;

(4) Sealing of the retina to the pigment epithelium by newly formed desmosomes without reversal of the destructive process. 


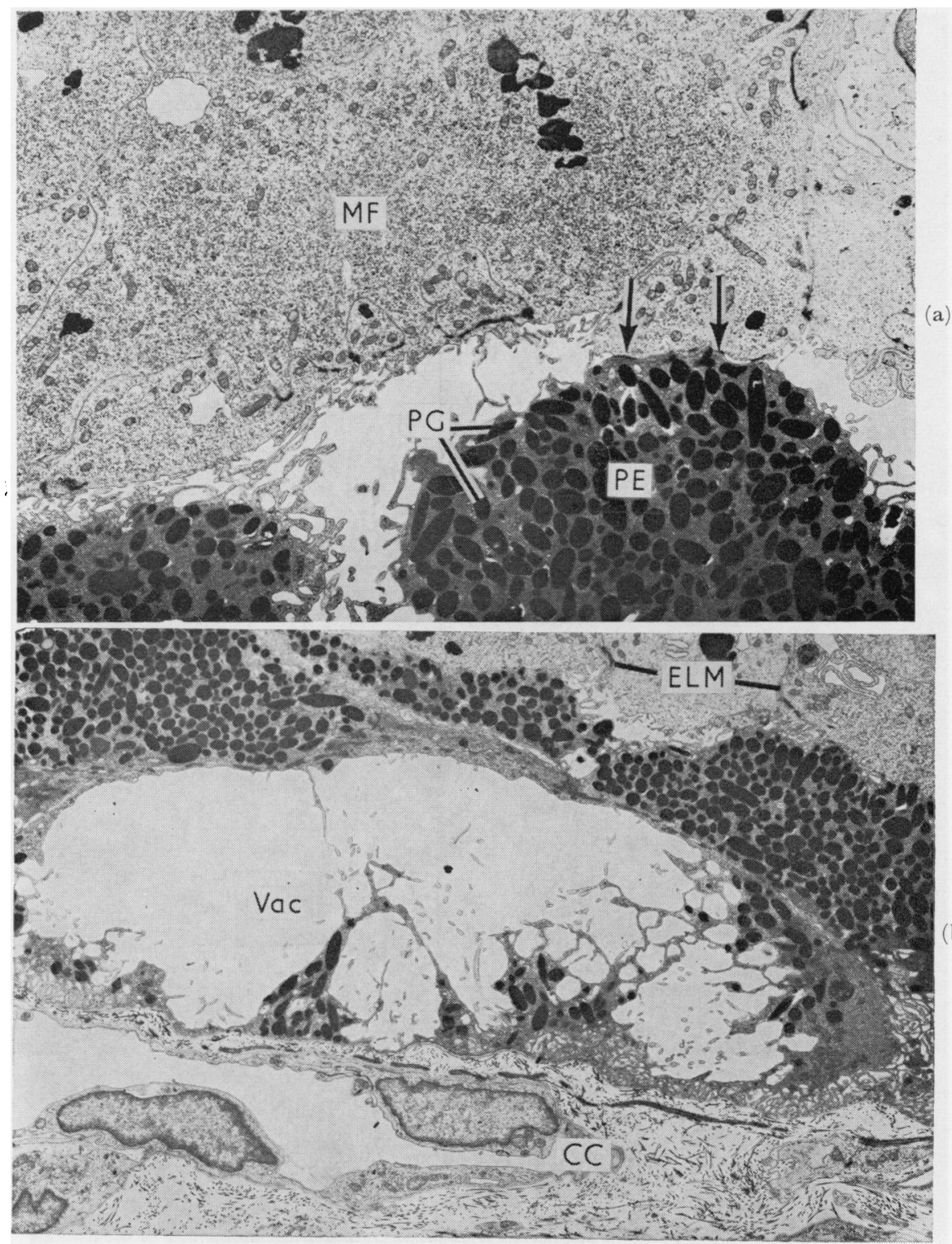

(b)

FIG. 14 I-minim intraocular injection of iron-dextran complex after I4 days.

(a) The pigment epithelium (PE) has proliferated and formed a mound of cells beneath the retina. Pigment granules (PG) are scattered throughout the cytoplasm and are absent from the microvilli. As the epithelial cells come in contact with Müller fibres (MF), the microvilli disappear and desmosomes (arrows) are formed. $\times 5,250$

(b) From same eye as $(a)$. Pigment epithelial cell with a large intracellular vacuole (Vac) which replaces almost the entire cell.

ELM, external limiting membrane; CC, choriocapillaris. $\quad \times 3,750$.

We acknowledge the technical assistance of Mrs. K. Cosentino, Miss C. Chase, and Mr. F. Pierre.

\section{References}

cibis, P. A., and yamashita, т. (1959) Amer. F. Ophthal., 48, no. 5, pt 2, p. 465

hogan, м. J., and zimmerman, L. E. (1962) "Ophthalmic Pathology", 2nd ed., p. 797. Saunders,

Philadelphia 


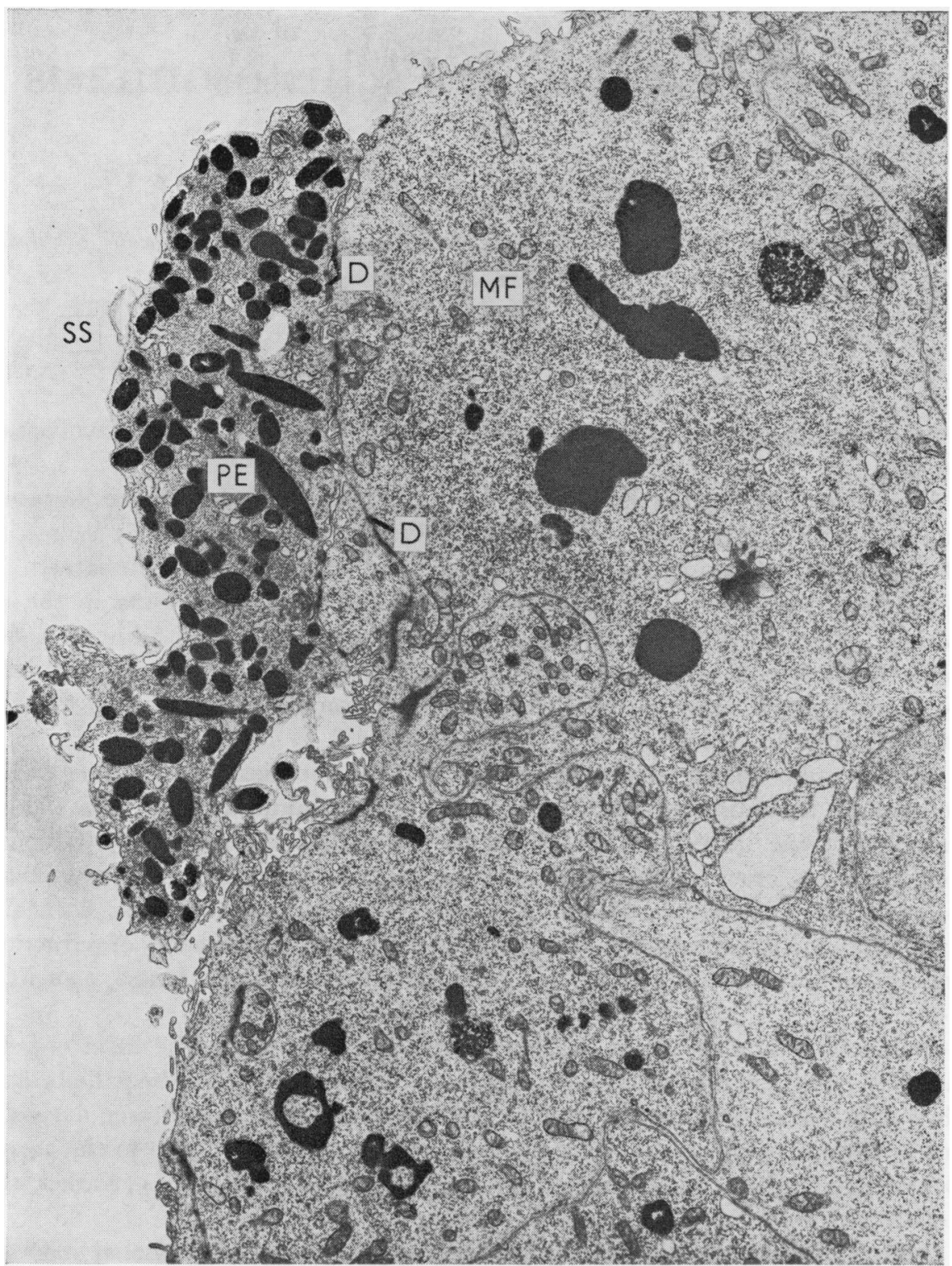

FIG. I5 I-minim intraocular injection of iron-dextran complex after i4 days. High-power electron micrograph, showing strength of retinal reattachment. The pigment epithelium $(P E)$ was accidentally torn from the choroid during preparation of this section, yet epithelial cells remained attached to the retina by the recently formed attachemnt zones (desmosomes) in spite of their original attachment to the choroid. Where the retina and epithelium are reattached, the brush borders of the Müller fibres $(M F)$ and the microvilli of the epithelium have disappeared.

$\mathrm{SS}$, subretinal space; $\mathrm{D}$, desmosome. $\times 8$,ooo

kroll, A. J., and MAchemer, R. (I969a) Amer. J. Ophthal., 67, i I 7

$$
\text { (1969b) Ibid., 68, } 58
$$

LILlIE, R. D. (1965) "Histopathologic Technic and Practical Histochemistry", 3rd ed. Blakiston

Division, McGraw-Hill, New York

MACHEMER, r. (1968) Amer. F. Ophthal., 66, 396

shakib, м., and AShton, N. (1966) Brit. F. Ophthal., 50, 325 
Orbital Fractures. By H. H. Hötтe. 1970. Pp. 394, 75 figs, bibl. Royal Vangorcum, Assen, The Netherlands. (Florins 74)

This valuable treatise begins with some discussion regarding the primary functions of the human face, including vision, respiration, smell, intake of food, and speech. The face also has aesthetic functions. The osteology of the face is described with special emphasis on the orbital walls. The anatomy of the orbital adnexa and the orbital contents is discussed. Fracture mechanisms and types of fracture are listed and their aetiology is presented. The importance of the careful clinical examination of patients is emphasized and the clinical record sheet used in Amsterdam is shown. The value of the opinions of otolaryngologists, neurologists, and plastic surgeons is stated. The various complications of facial injury are described, and the useful work of the orthoptic department is emphasized. Radiological examination of facial injuries is essential and this is described and illustrated. Many patients with facial injury suffer damage to the optic nerves with or without fractures of the optic canal. The treatment of all facial injuries is discussed and the surgical methods used are shown in detail. The book is concluded by statistical evaluation of 309 cases of orbital fracture, which shows most interesting results. The author also inserts a chapter on the responsibility of the ophthalmic surgeon in cases of orbital fracture.

\section{Notes}

\section{Sociedad Venezolana de Oftalmologia}

Officers, $197^{1-72}$

$\begin{array}{llll}\text { President: } & \text { Dr. Francisco Rodríguez Días } & \text { Secretary: } & \text { Dr. Guillermo Pereira } \\ \text { Vice-president }: & \text { Dr. Gustavo Ascanio Escobar } & \text { Treasurer: } & \text { Dr. Fernando Guarache Melo } \\ \text { Secretary General: } & \text { Dr. Gustavo Rodríguez Loreto } & \begin{array}{r}\text { Members of } \\ \text { the Board: }\end{array} & \text { Dr. Yamil Najul Saldivia } \\ & & \text { Dr. Euro de la Torre }\end{array}$

\section{Obituary}

\section{Edwin Harry Leonard Cook, 1916-197I}

E. H. L. Cook was one of the better known and best liked ophthalmologists in the north of England. He graduated at the University of Liverpool in $194^{\circ}$ and thereafter joined the Volunteer Reserve of the Royal Air Force. His final period of service was in India where he became attracted to ophthalmology, and on returning home he pursued that subject, becoming senior registrar in the (then) Eye, Ear and Throat Infirmary in Liverpool in 1947. After holding several surgical posts in the surrounding region, he became a consulting ophthalmic surgeon to St. Paul's Eye Hospital in Liverpool in 1958, and when his untimely death occurred he was senior consultant ophthalmic surgeon to the Liverpool Regional Hospital Board and the United Liverpool Hospitals and also lecturer in ophthalmology to his old university.

\section{Correction}

In the article by A. N. Barber, C. Catsulis, and R. J. Cangelosi, which appeared in the February issue (Brit. J. Ophthal. (r97r) 55, $9 \mathrm{I})$, please amend the following:

p. 93, 1. 7, for sytoplasm read cytoplasm

p. 98, 1. 3, for would read could

It is regretted that the authors' corrected proofs were delayed by the Post O.fice strike. 